\title{
Study of Temperature Effect on the Corrosion Inhibition of C38 Carbon Steel Using Amino-tris(Methylenephosphonic) Acid in Hydrochloric Acid Solution
}

\author{
Najoua Labjar, ${ }^{1,2}$ Fouad Bentiss, ${ }^{3}$ Mounim Lebrini, ${ }^{2}$ Charafeddine Jama, ${ }^{2}$ \\ and Souad El hajjaji ${ }^{1}$ \\ ${ }^{1}$ Laboratoire de Spectroscopie Infrarouge, Faculté des Sciences, University Med V Agdal, avenue Ibn Battouta, BP 1014, \\ Rabat 10000, Morocco \\ ${ }^{2}$ Unité Matériaux et Transformations (UMET), Ingénierie des Systèmes Polymères CNRS UMR 8207, ENSCL, BP 90108, \\ 59652 Villeneuve d'Ascq Cedex, France \\ ${ }^{3}$ Laboratoire de Chimie de Coordination et d'Analytique, Faculté des Sciences, Université Chouaib Doukkali, BP 20, \\ El Jadida 24000, Morocco
}

Correspondence should be addressed to Souad El hajjaji, selhajjaji@hotmail.com

Received 13 March 2011; Revised 17 July 2011; Accepted 12 August 2011

Academic Editor: Carmen Andrade

Copyright (C) 2011 Najoua Labjar et al. This is an open access article distributed under the Creative Commons Attribution License, which permits unrestricted use, distribution, and reproduction in any medium, provided the original work is properly cited.

Tafel polarization method was used to assess the corrosion inhibitive and adsorption behaviours of aminotris(methylenephosphonic) acid (ATMP) for C38 carbon steel in $1 \mathrm{M} \mathrm{HCl}$ solution in the temperature range from 30 to $60^{\circ} \mathrm{C}$. It was shown that the corrosion inhibition efficiency was found to increase with increase in ATMP concentration but decreased with temperature, which is suggestive of physical adsorption mechanism. The adsorption of the ATMP onto the C38 steel surface was found to follow Langmuir adsorption isotherm model. The corrosion inhibition mechanism was further corroborated by the values of kinetic and thermodynamic parameters obtained from the experimental data.

\section{Introduction}

Corrosion inhibition of steel in acid solutions by different types of inhibitors has been extensively studied. The use of environmentally acceptable inhibitors is favoured. Phosphonates are known to be environmentally friendly corrosion inhibitors, which form adsorbed layers on oxide- or hydroxide-covered metal surfaces [1-4]. Many works can be found in the literature about the interactions between phosphonates and iron or steels. In particular, Ochoa and al. $[2,4]$ studied the interaction between phosphonocarboxylic acid salts (monophosphonates) and carbon steel. Their environmental impact at usual concentrations for corrosion inhibition is negligible $[5,6]$. Moreover, in contrast to inorganic phosphorous compounds, they do not cause eutrophication. Their high stability to hydrolysis and resistance to degradation is also beneficial. It was found that few inhibitors with acid-metal systems have specific reactions that are still effective at high temperatures as (or more) they are at low temperatures $[7,8]$. A large number of investigations have studied the temperature effects on acidic corrosion and corrosion inhibition of iron and steel in $\mathrm{HCl}$ and $\mathrm{H}_{2} \mathrm{SO}_{4}$ solutions [9-17].

In previous work [1], the improving of the corrosion resistance of $\mathrm{C} 38$ carbon steel in $1 \mathrm{M} \mathrm{HCl}$ solution using ATMP has been investigated at $30^{\circ} \mathrm{C}$ by means of gravimetric and electrochemical (ac impedance and Tafel polarisation) methods. We have found that this compound is efficient inhibitor in $1 \mathrm{M} \mathrm{HCl}$ and the corrosion inhibition is mainly controlled by a physisorption process. The antibacterial activity investigations have been shown that the ATMP has an antibacterial effect against both Gram-positive and Gramnegative bacteria [1]. A great limitation of the inhibitor application is the fall down of their efficiencies at high temperatures. The effect of temperature on the inhibited acidmetal reaction is highly complex because many charges 
occur on the metal surface such as rapid etching and desorption of the inhibitor, and the inhibitor itself, in some cases, may undergo decomposition and/or rearrangement [18]. However, it provides the ability of calculating many thermodynamic functions for the inhibition and/or the adsorption processes which contribute in determining the type of adsorption of the studied inhibitor. The aim of this work is then to study the effect of temperature on C38 carbon steel corrosion process in $1 \mathrm{M} \mathrm{HCl}$ both in the absence and in the presence of amino-tris(methylenephosphonic) acid(ATMP) using Tafel polarisation method. The thermodynamic parameters for both activation and adsorption processes were calculated and discussed.

\section{Experimental Details}

The material used in this study is a C38 carbon steel with a chemical composition (in wt \%) of $0.370 \% \mathrm{C}, 0.230 \% \mathrm{Si}$, $0.680 \% \mathrm{Mn}, 0.016 \% \mathrm{~S}, 0.077 \% \mathrm{Cr}, 0.011 \% \mathrm{Ti}, 0.059 \% \mathrm{Ni}$, $0.009 \% \mathrm{Co}, 0.160 \% \mathrm{Cu}$, and the remainder iron $(\mathrm{Fe})$. The C38 carbon samples were pretreated prior to the experiments by grinding with emery paper $\operatorname{SiC}(120,600$, and 1200), rinsed with distilled water, degreased in acetone in an ultrasonic bath immersion for $5 \mathrm{~min}$, washed again with bidistilled water, and then dried at room temperature before use. The tested compound, namely amino-tris(methylenephosphonic) acid $\left(\mathrm{N}\left[\mathrm{CH}_{2} \mathrm{P}(\mathrm{O})(\mathrm{OH})_{2}\right]_{3}\right),(\mathrm{ATMP})$, obtained from Sigma-Aldrich ( 50 wt.\% in $\mathrm{H}_{2} \mathrm{O}$ ), was tested without further purification. The molecular structure of the ATMP is shown in Figure 1. The acid solutions $(1 \mathrm{M} \mathrm{HCl})$ were prepared by dilution of an analytical reagent grade $37 \% \mathrm{HCl}$ with doubly distilled water.

Polarisation curves were conducted using an electrochemical measurement system Tacussel-Radiometer model PGZ 301 potentiostat controlled by a PC and supported by Voltamaster 4.0 software. Electrochemical measurements were carried out in a conventional three-electrode cylindrical Pyrex glass cell. The temperature is thermostatically controlled. The working electrode (WE) in the form of disccut from steel has a geometric area of $1 \mathrm{~cm}^{2}$ and is embedded in polytetrafluoroethylene (PTFE). A saturated calomel electrode (SCE) and a platinum electrode were used, as reference and auxiliary electrodes, respectively. A fine Luggin capillary was placed close to the working electrode to mini-mize IR drop. All test solutions were deaerated in the cell by using pure nitrogen for $10 \mathrm{~min}$ prior to the experiment. During each experiment, the test solution was mixed with a magnetic stirrer, and the gas bubbling was maintained. The mild steel electrode was maintained at corrosion potential for $30 \mathrm{~min}$ and thereafter prepolarised at $-800 \mathrm{mV}_{\mathrm{SCE}}$ for $10 \mathrm{~min}$. The potentiodynamic current potential curves were obtained by changing the electrode potential automatically from -800 to $-200 \mathrm{mV}_{\mathrm{SCE}}$ with a scan rate of $0.5 \mathrm{mV} \mathrm{s}^{-1}$.

\section{Results and Discussion}

3.1. Corrosion Kinetic Study. In order to gain more information about the type of adsorption and the effectiveness

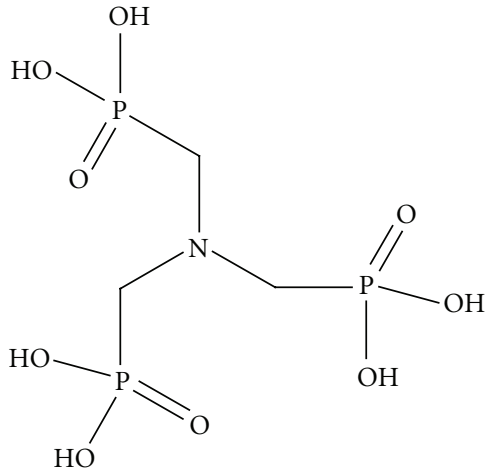

Figure 1: Molecular structure of the amino-tris(methylenephosphonic) acid (ATMP).

of the ATMP inhibitor at higher temperature, polarisation experiment was conducted in the range of $30-60^{\circ} \mathrm{C}$ without and with selected concentrations of the inhibitor. Representative Tafel polarisation curves for C38 steel electrode in $1 \mathrm{M} \mathrm{HCl}$ without and with $0.1 \mathrm{M}$ of ATMP at different temperatures are shown in Figure 2. Similar polarisation curves were obtained in the case of the other concentrations of ATMP (not given). The analysis of these figures reveals that raising the temperature increases both anodic and cathodic current densities, and consequently the corrosion rate of C38 steel increases.

Electrochemical kinetic parameters (corrosion potential $\left(E_{\text {corr }}\right)$, corrosion current density $\left(I_{\text {corr }}\right)$, and cathodic Tafel slope $\left(b_{c}\right)$ ), determined from these experiments by extrapolation method [19-23], are reported in Table 1. The $I_{\text {corr }}$ was determined by Tafel extrapolation of only the cathodic polarization curve alone, which usually produces a longer and better defined Tafel region [24]. The inhibition efficiencies, $E(\%)$, are calculated from $I_{\text {corr }}$ values as described elsewhere [18]. The surface coverage $\theta$ was calculated from the following equation [25]:

$$
\theta=\frac{I_{\text {corr }}-I_{\text {corr }(\mathrm{inh})}}{I_{\mathrm{corr}}-I_{\mathrm{sat}}},
$$

where $I_{\text {corr }}, I_{\text {corr(inh), }}$, and $I_{\text {sat }}$ are the corrosion current density values in the absence, the presence of ATMP, and in an entirely covered surface, respectively, $\left(I_{\text {sat }}=I_{\text {corr }}\right.$ for the most elevated concentration of inhibitor).

$$
\text { As } I_{\text {sat }} \ll I_{\text {corr }} \text {, thus }
$$

$$
\theta=\frac{I_{\text {corr }}-I_{\text {corr }(\mathrm{inh})}}{I_{\text {corr }}} .
$$

Analyse of the results in Table 1 indicates that in the presence of ATMP molecules, the $I_{\text {corr }}$ of C38 steel decreases at any given temperature as inhibitor concentration increases compared to the uninhibited solution, due to the increase of the surface coverage degree. In contrast, at constant ATMP concentration, the $I_{\text {corr }}$ increases as temperature rises, but this increase is more pronounced for the blank solu-tion. Hence we can note that the $E(\%)$ depends on the temperature and decreases with the rise of temperature from 30 to 
TABLE 1: Electrochemical parameters and the corresponding inhibition efficiencies at various temperatures studied of C38 steel in $1 \mathrm{M} \mathrm{HCl}$ containing different concentrations of ATMP.

\begin{tabular}{|c|c|c|c|c|c|c|}
\hline Temperature $\left(\mathrm{C}^{\circ}\right)$ & Conc. (M) & $E_{\text {corr }}$ versus SCE $\mathrm{mV}$ & $I_{\text {corr }}\left(\mu \mathrm{A} \mathrm{cm}^{-2}\right)$ & $b_{\mathrm{c}}\left(\mathrm{mV} \mathrm{\operatorname {dec } ^ { - 1 } )}\right.$ & $E(\%)$ & $\theta$ \\
\hline \multirow{5}{*}{30} & $1 \mathrm{M} \mathrm{HCl}$ & -482 & 569.8 & 188 & - & - \\
\hline & $5 \times 10^{-5}$ & -482 & 477.8 & 186 & 16.1 & 0.16 \\
\hline & $5 \times 10^{-3}$ & -473 & 175.4 & 146 & 69.2 & 0.69 \\
\hline & $5 \times 10^{-2}$ & -471 & 109.3 & 128 & 80.8 & 0.81 \\
\hline & $1 \times 10^{-1}$ & -464 & 76.7 & 122 & 86.5 & 0.87 \\
\hline \multirow{5}{*}{40} & $1 \mathrm{M} \mathrm{HCl}$ & -464 & 800.7 & 190 & - & - \\
\hline & $5 \times 10^{-5}$ & -470 & 700.3 & 189 & 12.5 & 0.13 \\
\hline & $5 \times 10^{-3}$ & -452 & 478.7 & 154 & 40.2 & 0.40 \\
\hline & $5 \times 10^{-2}$ & -471 & 308.3 & 132 & 61.5 & 0.61 \\
\hline & $1 \times 10^{-1}$ & -462 & 235.3 & 129 & 70.6 & 0.71 \\
\hline \multirow{5}{*}{50} & $1 \mathrm{M} \mathrm{HCl}$ & -461 & 999.1 & 191 & - & - \\
\hline & $5 \times 10^{-5}$ & -455 & 875.9 & 188 & 12.3 & 0.12 \\
\hline & $5 \times 10^{-3}$ & -463 & 737.2 & 166 & 26.2 & 0.26 \\
\hline & $5 \times 10^{-2}$ & -464 & 572.7 & 145 & 42.7 & 0.43 \\
\hline & $1 \times 10^{-1}$ & -454 & 407.9 & 134 & 59.2 & 0.59 \\
\hline \multirow{5}{*}{60} & $1 \mathrm{M} \mathrm{HCl}$ & -465 & 1314.7 & 194 & - & - \\
\hline & $5 \times 10^{-5}$ & -456 & 1195.5 & 191 & 9.0 & 0.09 \\
\hline & $5 \times 10^{-3}$ & -461 & 1046.9 & 187 & 20.4 & 0.20 \\
\hline & $5 \times 10^{-2}$ & -453 & 788.0 & 167 & 40.1 & 0.40 \\
\hline & $1 \times 10^{-1}$ & -445 & 651.1 & 152 & 50.5 & 0.50 \\
\hline
\end{tabular}

$60^{\circ} \mathrm{C}$. This can be explained by the decrease of the strength of the adsorption process at elevated temperature and would suggest a physical adsorption mode.

The activation parameters for the corrosion reaction can be regarded as an Arrhenius-type process, according to the following equation:

$$
I_{\text {corr }}=A \exp \left(-\frac{E_{\mathrm{a}}}{R T}\right)
$$

where $E_{\mathrm{a}}$ is the apparent activation corrosion energy, $R$ is the universal gas constant, and $A$ is the Arrhenius preexponential factor. The apparent activation energies $\left(E_{\mathrm{a}}\right)$ in the absence and in the presence of various concentrations of ATMP are calculated by linear regression between $\ln \left(I_{\text {corr }}\right)$ and $1 / T$ (Figure 3), and the results are given in Table 2. All the linear regression coefficients are close to 1 , indicating that the steel corrosion in hydrochloric acid can be elucidated using the kinetic model. As observed from Table 2, the $E_{\mathrm{a}}$ increased with increasing concentration of ATMP, but all values of $E_{\mathrm{a}}$ in the range of the studied concentration were higher than that of the uninhibited solution. The increase in $E_{\mathrm{a}}$ in the presence of ATMP may be interpreted as physical adsorption. Indeed, a higher energy barrier for the corrosion process in the inhibited solution is associated with physical adsorption or weak chemical bonding between the inhibitor species and the steel surface $[14,26]$. Szauer and Brand. explained that the increase in activation energy can be attributed to an appreciable decrease in the adsorption of the inhibitor on the carbon steel surface with the increase in temperature. A corresponding increase in the corrosion rate occurs because of
TABLE 2: Corrosion kinetic parameters for C38 steel in $1 \mathrm{M} \mathrm{HCl}$ in absence and presence of different concentrations of ATMP.

\begin{tabular}{lcccc}
\hline $\begin{array}{l}\text { Concentration } \\
(\mathrm{M})\end{array}$ & $\begin{array}{c}E_{\mathrm{a}} \\
\left(\mathrm{kJ} \mathrm{mol}^{-1}\right)\end{array}$ & $\begin{array}{c}\Delta H_{\mathrm{a}} \\
\left(\mathrm{kJ} \mathrm{mol}^{-1}\right)\end{array}$ & $\begin{array}{c}\Delta S_{\mathrm{a}} \\
\left(\mathrm{J} \mathrm{mol}^{-1} \mathrm{k}^{-1}\right)\end{array}$ & $\begin{array}{c}E_{\mathrm{a}}-\Delta H_{\mathrm{a}} \\
\left(\mathrm{kJ} \mathrm{mol}^{-1}\right)\end{array}$ \\
\hline Blank & 22.92 & 20.28 & -125.22 & 2.64 \\
$5 \times 10^{-5}$ & 24.98 & 22.34 & -119.84 & 2.64 \\
$5 \times 10^{-3}$ & 48.90 & 46.26 & -48.05 & 2.64 \\
$5 \times 10^{-2}$ & 55.25 & 52.62 & -31.04 & 2.63 \\
$1 \times 10^{-1}$ & 58.75 & 56.11 & -22.43 & 2.64 \\
\hline
\end{tabular}

the greater area of metal that is consequently exposed to the acid environment [27].

The enthalpy of activation $\left(\Delta H_{\mathrm{a}}\right)$ and the entropy of activation $\left(\Delta S_{\mathrm{a}}\right)$ for the intermediate complex in the transition state for the corrosion of C38 steel in $1 \mathrm{M} \mathrm{HCl}$ in the absence and in the presence of different concentrations of ATMP were obtained by applying the alternative formulation of Arrhenius equation [28]:

$$
I_{\text {corr }}=\frac{R T}{N h} \exp \left(\frac{\Delta S_{\mathrm{a}}}{R}\right) \exp \left(-\frac{\Delta H_{\mathrm{a}}}{R T}\right),
$$

where $h$ is the Plank's constant and $N$ is the Avogadro's number. Figure 4 shows a plot of $\ln \left(I_{\text {corr }} / T\right)$ versus $1 / T$. A straight lines are obtained with a slope of $\left(-\Delta H_{\mathrm{a}} / R\right)$ and an intercept of $\left(\ln R / N h+\Delta S_{\mathrm{a}} / R\right)$ from which the values of $\Delta H_{\mathrm{a}}$ and $\Delta S_{\mathrm{a}}$ were calculated (Table 2). The positive values of $\Delta H_{\mathrm{a}}$ in the absence and the presence of ATMP reflect the endothermic nature of the $\mathrm{C} 38$ steel dissolution process. One can also notice that $E_{\mathrm{a}}$ and $\Delta H_{\mathrm{a}}$ values vary in the same way 


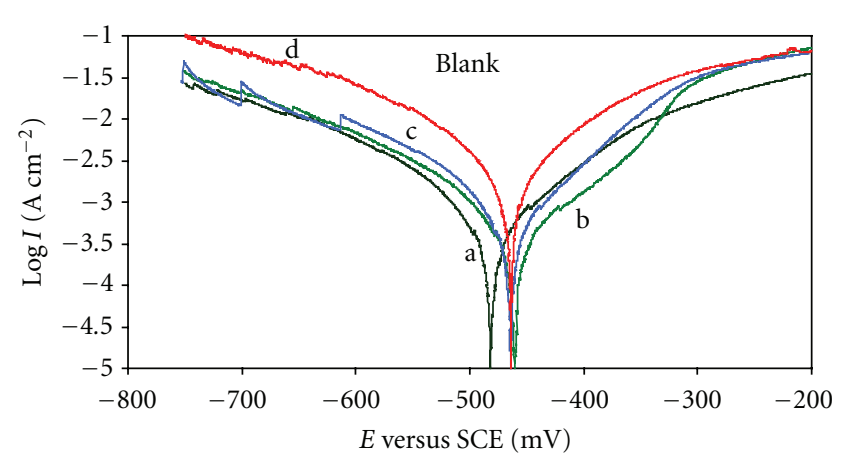

(a)

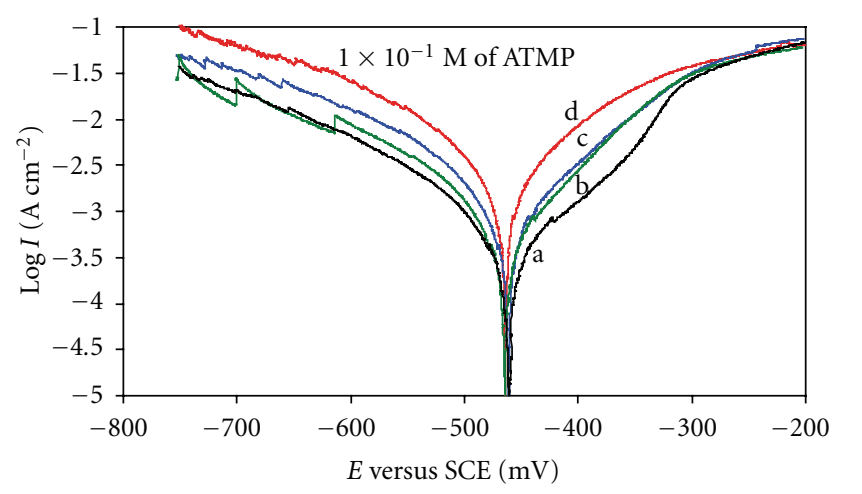

$\begin{array}{ll}\text { a: } 30^{\circ} \mathrm{C} & \text { c: } 50^{\circ} \mathrm{C} \\ \text { b: } 40^{\circ} \mathrm{C} & \text { d: } 60^{\circ} \mathrm{C}\end{array}$

(b)

FIGURE 2: Effect of temperature on the cathodic and anodic responses for $\mathrm{C} 38$ steel in $1 \mathrm{M} \mathrm{HCl}$ and $1 \mathrm{M} \mathrm{HCl}+0.1 \mathrm{M}$ of ATMP.

as shown in Table 2, indicating that the corrosion process is a unimolecular reaction [29]. This result permits verifying the known thermodynamic equation between the $E_{\mathrm{a}}$ and $\Delta H_{\mathrm{a}}$ [29]

$$
E_{\mathrm{a}}-\Delta H_{\mathrm{a}}=R T \text {. }
$$

The values of activation entropy $\left(\Delta S_{\mathrm{a}}\right)$ are higher for inhibited solutions than that for the uninhibited solution and increase gradually with increasing ATMP concentrations (Table 2). The positive increment of $\Delta S_{\mathrm{a}}$ suggests that an increase in randomness occurred on going from reactants to the activated complex [30]. This observation is in agreement with the findings of other workers $[30,31]$.

\subsection{Adsorption Isotherm and Thermodynamic Parameters.}

The values of surface coverage $\theta$ corresponding to different concentrations of AMTP in the temperature range from 30 to $60^{\circ} \mathrm{C}$ have been used to explain the best isotherm to determine the adsorption process. As it is known that the adsorption of an organic adsorbate onto metal-solution interface can be presented as a substitutional adsorption process between the organic molecules in the aqueous solution
$\mathrm{Org}_{(\text {sol })}$ and the water molecules on the metallic surface $\mathrm{H}_{2} \mathrm{O}_{(\mathrm{ads})}$,

$$
\mathrm{Org}_{(\mathrm{sol})}+n \mathrm{H}_{2} \mathrm{O}_{(\mathrm{ads})} \longleftrightarrow \mathrm{Org}_{(\mathrm{ads})}+n \mathrm{H}_{2} \mathrm{O}_{(\mathrm{sol})},
$$

where $\mathrm{Org}_{(\mathrm{sol})}$ and $\mathrm{Org}_{(\mathrm{ads})}$ are the organic molecules in the aqueous solution and adsorbed on the metallic surface, respectively, $\mathrm{H}_{2} \mathrm{O}_{(\text {ads })}$ is the water molecules on the metallic surface, and $n$ is the size ratio representing the number of water molecules replaced by one molecule of organic adsorbate. When the equilibrium of the process described in this equation is reached, it is possible to obtain different expressions of the adsorption isotherm plots, and thus the surface coverage degree $(\theta)$ can be plotted as a function of the concentration of the inhibitor under test [32]. The Langmuir adsorption isotherm was found to give the best description of the adsorption behaviour of ATMP. In this case, the surface coverage $(\theta)$ of the inhibitor on the steel surface is related to the concentration of inhibitor in the solution according to the following equation:

$$
\frac{\theta}{1-\theta}=K_{\mathrm{ads}} C_{\mathrm{inh}}
$$

Rearranging this equation gives

$$
\frac{C_{\mathrm{inh}}}{\theta}=\frac{1}{K_{\mathrm{ads}}}+C_{\mathrm{inh}}
$$

where $\theta$ is the surface coverage degree, $C_{\text {inh }}$ is the inhibitor concentration in the electrolyte, and $K_{\mathrm{ads}}$ is the equilibrium constant of the adsorption process. The $K_{\text {ads }}$ values may be taken as a measure of the strength of the adsorption forces between the inhibitor molecules and the metal surface [33]. To calculate the adsorption parameters, the straight lines were drawn using the least squares method. The experimental (points) and calculated isotherms (lines) are plotted in Figure 5. The results are presented in Table 3. A very good fit is observed with a regression coefficient $\left(R^{2}\right)$ up to 0.99 and the obtained lines have slopes very close to unity, which suggests that the experimental data are well described by Langmuir isotherm and exhibit single-layer adsorption characteristic [18]. This kind of isotherm involves the assumption of no interaction between the adsorbed species and the electrode surface. From the intercepts of the straight lines $C_{\text {inh }} / \theta$-axis, the $K_{\text {ads }}$ values were calculated and given in Table 3 . As can be seen from Table $3, K_{\text {ads }}$ values decrease with increasing temperature from 30 to $60^{\circ} \mathrm{C}$. Such behaviour can be interpreted on the basis that the increase in temperature results in desorption of some adsorbed inhibitor molecules from the metal surface [18].

The well-known thermodynamic adsorption parameters are the free energy of adsorption $\left(\Delta G_{\text {ads }}^{\mathrm{o}}\right)$, the standard enthalpy of adsorption $\left(\Delta H_{\mathrm{ads}}^{\mathrm{o}}\right)$, and the entropy of adsorption $\left(\Delta S_{\text {ads }}^{\mathrm{o}}\right)$. These quantities can be calculated depending on the estimated values of $K_{\mathrm{ads}}$ from adsorption isotherms, at different temperatures. The constant of adsorption, $K_{\mathrm{ads}}$, is related to the standard free energy of adsorption, $\Delta G_{\text {ads }}^{\mathrm{o}}$, with the following equation [34]:

$$
K_{\mathrm{ads}}=\frac{1}{55.5} \exp \left(\frac{-\Delta G_{\mathrm{ads}}^{\mathrm{o}}}{R T}\right)
$$




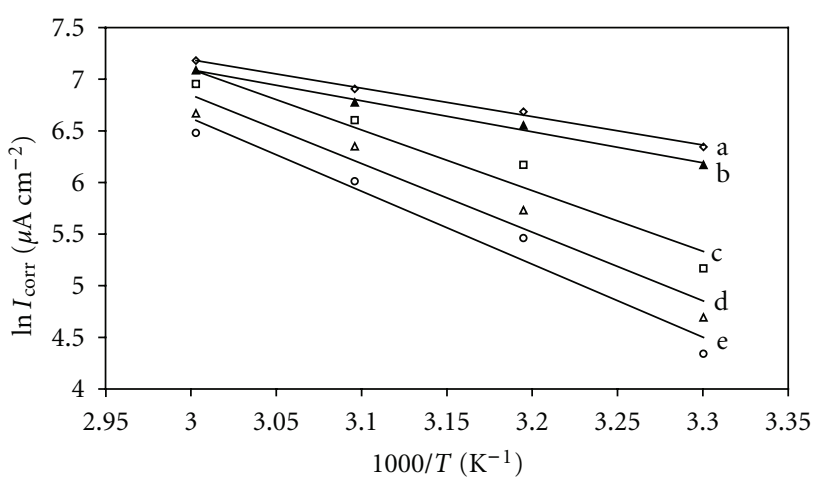

$$
\begin{array}{ll}
\text { a: Blank } & \text { d: } 5 \times 10^{-2} \mathrm{M} \\
\text { b: } 5 \times 10^{-5} \mathrm{M} & \text { e: } 1 \times 10^{-1} \mathrm{M} \\
\text { c: } 5 \times 10^{-3} \mathrm{M} &
\end{array}
$$

FIGURE 3: Arrhenius plots for C38 steel corrosion rates $\ln I_{\text {corr }}$ versus $1 / T$ in $1 \mathrm{M} \mathrm{HCl}$ in absence and in presence of different concentrations of ATMP.

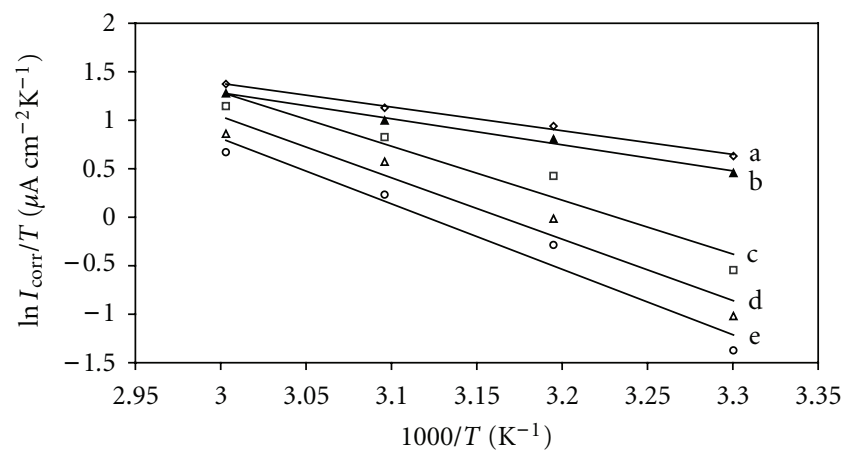

$$
\begin{array}{ll}
\text { a: Blank } & \text { d: } 5 \times 10^{-2} \mathrm{M} \\
\text { b: } 5 \times 10^{-5} \mathrm{M} & \text { e: } 1 \times 10^{-1} \mathrm{M} \\
\text { c: } 5 \times 10^{-3} \mathrm{M} &
\end{array}
$$

Figure 4: Transition-state plots for C38 steel corrosion rates $\ln I_{\text {corr }}$ versus $1 / T$ in $1 \mathrm{M} \mathrm{HCl}$ in absence and in presence of different concentrations of ATMP.

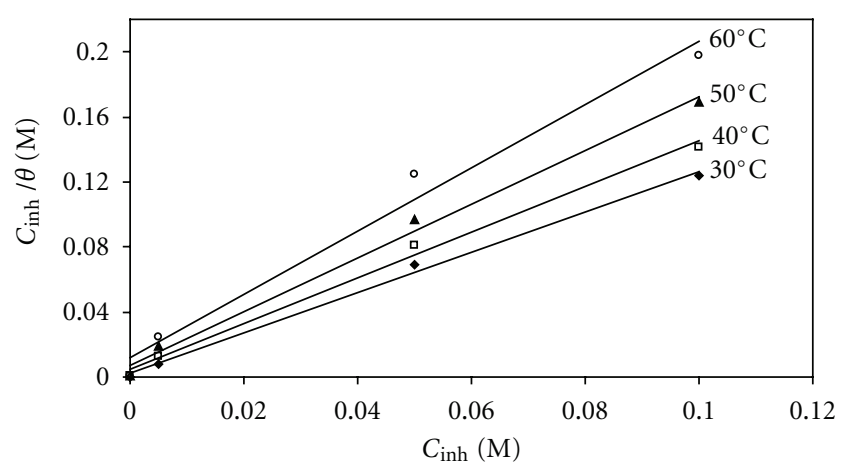

FIGURE 5: Langmuir's isotherm adsorption model of ATMP on the C38 steel surface in $1 \mathrm{M} \mathrm{HCl}$ at different temperatures. where $R$ is the universal gas constant, $T$ is the thermodynamic temperature, and the value of 55.5 is the concentration of water in the solution in $\mathrm{mol} / \mathrm{L}$. The calculated $\Delta G_{\text {ads }}^{\mathrm{o}}$ values, at all studied temperatures, are given in Table 3. The negative values of $\Delta G_{\text {ads }}^{\mathrm{o}}$ indicate the spontaneity of the adsorption process and the stability of the adsorbed layer on the C38 steel surface [16]. Generally, the adsorption type is regarded as physisorption if the absolute value of $\Delta G_{\mathrm{ads}}^{\mathrm{o}}$ is in the range of $20 \mathrm{~kJ} \mathrm{~mol}^{-1}$ or lower. The inhibition behaviour is attributed to the electrostatic interaction between the organic molecules and steel surface. When the absolute value of $\Delta G_{\text {ads }}^{\mathrm{o}}$ is in the order of $40 \mathrm{~kJ} \mathrm{~mol}^{-1}$ or higher, the adsorption could be seen as chemisorption. In this process, the covalent bond is formed by the charge sharing or transferring from the inhibitor molecules to the metal surface $[35,36]$. The obtained $\Delta G_{\text {ads }}^{\mathrm{o}}$ values in the studied temperature domain are in the range of -23.5 to $-26.5 \mathrm{~kJ} \mathrm{~mol}^{-1}$, indicating, therefore, that the adsorption mechanism of the ATMP onto C38 steel in $1 \mathrm{M} \mathrm{HCl}$ solution is mainly due to physisorption (Table 3). This behaviour is in good agreement with that obtained at $30^{\circ} \mathrm{C}$ using ac impedance technique [1]. On the other hand, the obtained values of $\Delta G_{\text {ads }}^{o}$ show a regular dependence on temperature, indicating a good correlation among thermodynamic parameters. However, a limited decrease in the absolute value of $\Delta G_{\text {ads }}^{o}$ with the increase in temperature values is observed. This behaviour is explained by the fact that the adsorption is somewhat unfavourable with increasing experimental temperature, indicating that the physisorption has the major contribution while the chemisorption has a minor contribution in the corrosion inhibition mechanism [37]. The other thermodynamic functions $\left(\Delta H_{\mathrm{ads}}^{\mathrm{o}}\right.$ and $\left.\Delta S_{\mathrm{ads}}^{\mathrm{o}}\right)$ can be calculated from the following equation:

$$
\Delta G_{\mathrm{ads}}^{\mathrm{o}}=\Delta H_{\mathrm{ads}}^{\mathrm{o}}-T \Delta S_{\mathrm{ads}}^{\mathrm{o}} .
$$

Figure 6 shows the plot of $\Delta G_{\text {ads }}^{o}$ versus $T$ which gives straight lines with slopes of $-\Delta S_{\text {ads }}^{o}$ and intercepts of $\Delta H_{\text {ads }}^{o}$. The obtained values of $\Delta H_{\mathrm{ads}}^{\mathrm{o}}$ and $\Delta S_{\mathrm{ads}}^{\mathrm{o}}$ are given in Table 3. The obtained value of $\Delta H_{\text {ads }}^{\mathrm{o}}$ is negative, reflecting the exothermic nature of the adsorption process on C38 steel surface. The value of $\Delta H_{\text {ads }}^{\mathrm{o}}$ can also provide valuable information about the type of inhibitor adsorption. While an endothermic adsorption process $\left(\Delta H_{\mathrm{ads}}^{\mathrm{o}}>0\right)$ is attributed unequivocally to chemisorption [38], an exothermic adsorption process $\left(\Delta H_{\mathrm{ads}}^{\mathrm{o}}<0\right)$ may involve either physisorption or chemisorption or a mixture of both the processes. In an exothermic process, chemisorption is distinguished from physisorption by considering the absolute value of $\Delta H_{\mathrm{ads}}^{\mathrm{o}}$. For the chemisorption process, $\Delta H_{\mathrm{ads}}^{\mathrm{o}}$ approaches $100 \mathrm{~kJ} \mathrm{~mol}^{-1}$, while for the physisorption process, it is less than $40 \mathrm{~kJ} \mathrm{~mol}^{-1}$ [37]. In the case of ATMP, the calculated value of $\Delta H_{\mathrm{ads}}^{\mathrm{o}}\left(-56.56 \mathrm{~kJ} \mathrm{~mol}^{-1}\right)$ is larger than the common physical adsorption enthalpy, but smaller than the commonchemical adsorption enthalpy, confirming that the adsorption mechanism of ATMP on carbon steel surface probably involves two types of interactions, predominant physisorption (ionic), and weak chemisorption (molecular). The value of $\Delta S_{\text {ads }}^{\mathrm{o}}$ is negative (Table 3), meaning that the inhibitor 


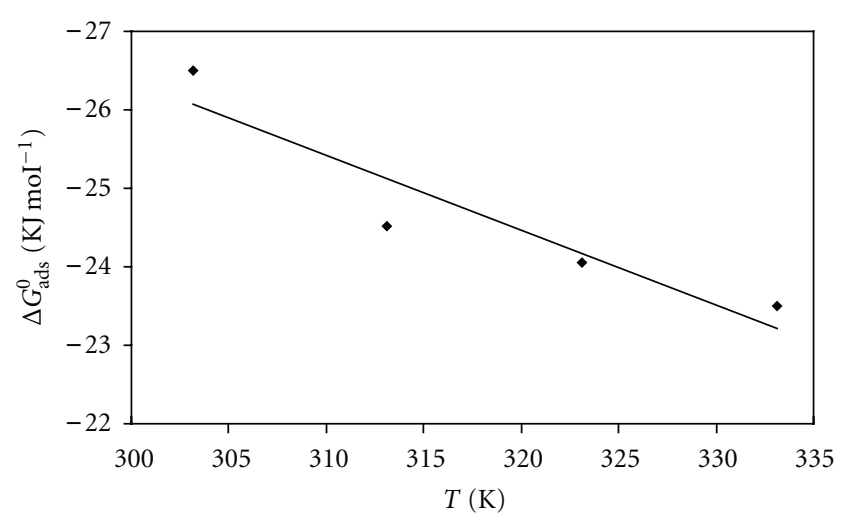

Figure 6: Variation of $\Delta G_{\text {ads }}^{\mathrm{o}}$ versus $T$ on C38 steel in $1 \mathrm{M} \mathrm{HCl}$ containing ATMP.

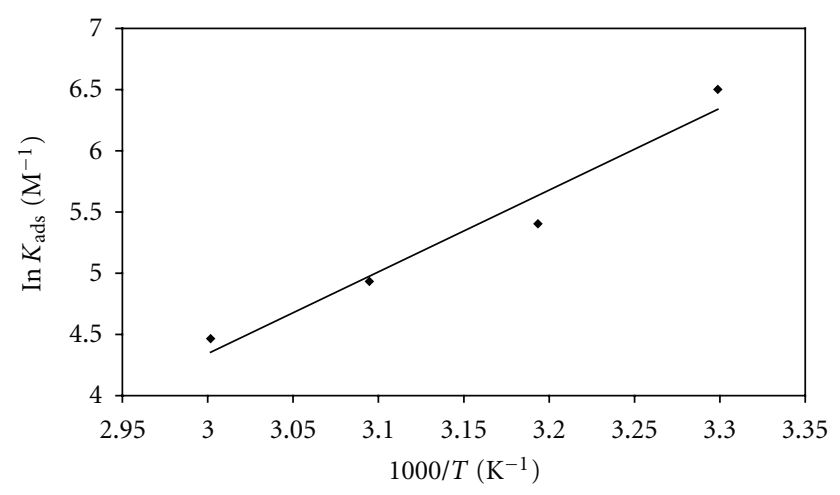

Figure 7: Vant't Hoff plot for the C38 steel/ATMP/1 M HCl.

molecules move freely in the bulk solution (are chaotic) before adsorption, while as adsorption progresses, the inhibitor molecules adsorbed onto the mild steel surface become more orderly, resulting in a decrease in entropy [39].

$\Delta H_{\mathrm{ads}}^{\mathrm{o}}$ and $\Delta S_{\mathrm{ads}}^{\mathrm{o}}$ can be also deduced from the integrated version of the Van't Hoff equation expressed by [40]

$$
\ln K_{\mathrm{ads}}=-\frac{\Delta H_{\mathrm{ads}}^{\mathrm{o}}}{R T}+\text { constant. }
$$

Figure 7 shows the plot of $\ln K_{\text {ads }}$ versus $1 / T$ which gives straight lines with slopes of $\left(-\Delta H_{\mathrm{ads}}^{\mathrm{o}} / R\right)$ and intercepts of $\left(\Delta S_{\text {ads }}^{\mathrm{o}} / R+\ln 1 / 55.5\right)$. The calculated $\Delta H_{\text {ads }}^{\mathrm{o}}$ using the $\operatorname{Van}^{\prime} \mathrm{t}$ Hoff equation is $-55.55 \mathrm{~kJ} \mathrm{~mol}^{-1}$ for ATMP, confirming the physisorption process and the exothermic behaviour of the adsorption of the ATMP molecule on the steel surface. Values of $\Delta H_{\text {ads }}^{\mathrm{o}}$ obtained by both methods are in good agreement. Moreover, the deduced $\Delta S_{\text {ads }}^{\mathrm{o}}$ value of $-97.16 \mathrm{~J} \mathrm{~mol}^{-1} \mathrm{~K}^{-1}$ for ATMP is very close to that obtained in Table 3.

\section{Conclusion}

We studied the inhibitor action of ATMP on corrosion of C38 steel in $1 \mathrm{M} \mathrm{HCl}$ depending on effect of temperature. We obtained the following conclusion.
TABLE 3: Thermodynamic parameters for the adsorption of ATMP on the $\mathrm{C} 38$ steel in $1 \mathrm{M} \mathrm{HCl}$ at different temperatures.

\begin{tabular}{lccccc}
\hline $\begin{array}{l}\text { Temperature } \\
(\mathrm{K})\end{array}$ & $R^{2}$ & $\begin{array}{c}K_{\mathrm{ads}} \\
\left(\mathrm{M}^{-1}\right)\end{array}$ & $\begin{array}{c}\Delta G_{\mathrm{ads}}^{\mathrm{o}} \\
\left(\mathrm{kJ} \mathrm{mol}^{-1}\right)\end{array}$ & $\begin{array}{c}\Delta H_{\mathrm{ads}}^{\mathrm{o}} \\
\left(\mathrm{kJ} \mathrm{mol}^{-1}\right)\end{array}$ & $\begin{array}{c}\Delta S_{\mathrm{ads}}^{\mathrm{o}} \\
\left(\mathrm{J} \mathrm{mol}^{-1} \mathrm{~K}^{-1}\right)\end{array}$ \\
\hline 30 & 0.99 & 666.7 & -26.50 & & \\
40 & 0.99 & 222.2 & -24.52 & -54.87 & -95.00 \\
50 & 0.99 & 138.9 & -24.04 & & \\
60 & 0.98 & 86.9 & -23.49 & & \\
\hline
\end{tabular}

(1) Based on the Tafel polarization results, the $E$ (\%) of ATMP is found to decrease with increasing temperature, and its addition to $1 \mathrm{M} \mathrm{HCl} \mathrm{leads} \mathrm{to} \mathrm{an} \mathrm{increase}$ of apparent activation energy $\left(E_{\mathrm{a}}\right)$ of the corrosion process.

(2) The corrosion process is inhibited by the adsorption of ATMP on C38 steel surface. This adsorption fits a Langmuir isotherm model. Thermodynamic adsorption parameters show that ATMP is adsorbed on steel surface by an exothermic and spontaneous process.

(3) The calculated values of $\Delta G_{\mathrm{ads}}^{\mathrm{o}}$ and $\Delta H_{\mathrm{ads}}^{\mathrm{o}}$ corroborate that the adsorption mechanism of ATMP on steel surface in $1 \mathrm{M} \mathrm{HCl}$ solution is mainly due to physisorption.

(4) At temperatures higher than $30^{\circ} \mathrm{C}$, this inhibitor is not efficient to control the corrosion of steel in $1 \mathrm{M}$ $\mathrm{HCl}$ at the concentration range studied.

\section{References}

[1] N. Labjar, M. Lebrini, F. Bentiss, N. E. Chihib, S. E. Hajjaji, and C. Jama, "Corrosion inhibition of carbon steel and antibacterial properties of aminotris-(methylenephosphonic) acid," Materials Chemistry and Physics, vol. 119, no. 1-2, pp. 330-336, 2010.

[2] N. Ochoa, G. Baril, F. Moran, and N. Pébère, "Study of the properties of a multi-component inhibitor used for water treatment in cooling circuits," Journal of Applied Electrochemistry, vol. 32, no. 5, pp. 497-504, 2002.

[3] A. Pilbáth, I. Bertóti, I. Sajó, L. Nyikos, and E. Kálmán, "Diphosphonate thin films on zinc: preparation, structure characterization and corrosion protection effects," Applied Surface Science, vol. 255, no. 5, pp. 1841-1849, 2008.

[4] N. Ochoa, F. Moran, and N. Pébère, "The synergistic effect between phosphonocarboxylic acid salts and fatty amines for the corrosion protection of a carbon steel," Journal of Applied Electrochemistry, vol. 34, no. 5, pp. 487-493, 2004.

[5] H. S. Awad and S. Turgoose, "Influence of hardness salts on the effectiveness of xinc-1 hydroxyethylidene 1,1 diphosphonic acid (HEDP) mixtures in inhibiting the corrosion of mild steel in neutral oxygen-containing solutions," Corrosion, vol. 60, no. 12, pp. 1168-1179, 2004.

[6] J. Jaworska, H. van Genderen-Takken, A. Hanstveit, E. van de Plassche, and T. Feijtel, "Environmental risk assessment of phosphonates, used in domestic laundry and cleaning agents in the Netherlands," Chemosphere, vol. 47, no. 6, pp. 655-665, 2002. 
[7] M. M. Singh and A. Gupta, "Inhibition of mild steel corrosion in formic acid solution," Bulletin of Electrochemistry, vol. 12, no. 9, pp. 511-516, 1996.

[8] M. H. Wahdan, A. A. Hermas, and M. S. Morad, "Corrosion inhibition of carbon-steels by propargyltriphenylphosphonium bromide in $\mathrm{H} 2 \mathrm{SO} 4$ solution," Materials Chemistry and Physics, vol. 76, no. 2, pp. 111-118, 2002.

[9] S. T. Arab and E. A. Noor, "Inhibition of acid corrosion of steel by some S-alkylisothiouronium iodides," Corrosion, vol. 49, no. 2, pp. 122-129, 1993.

[10] Z. Jiang, J. Wang, Q. Hu, and S. Huang, "The influence of 1-(2pyridylazo)-2-naphthol (PAN) on the corrosion of titanium in $10 \mathrm{~N}$ sulfuric acid solution," Corrosion Science, vol. 37, no. 8, pp. 1245-1252, 1995.

[11] F. Bentiss, M. Traisnel, L. Gengembre, and M. Lagrenée, "New triazole derivative as inhibitor of the acid corrosion of mild steel: electrochemical studies, weight loss determination, SEM and XPS," Applied Surface Science, vol. 152, no. 3, pp. 237-249, 1999.

[12] S. S. Abd El-Rehim, S. A. M. Refaey, F. Taha, M. B. Saleh, and R. A. Ahmed, "Corrosion inhibition of mild steel in acidic medium using 2-amino thiophenol and 2-cyanomethyl benzothiazole," Journal of Applied Electrochemistry, vol. 31, no. 4, pp. 429-435, 2001.

[13] S. T. Arab and A. M. Al-Turkustani, International Journalof Chemistry, vol. 12, p. 249, 2002.

[14] A. Popova, E. Sokolova, S. Raicheva, and M. Christov, "AC and DC study of the temperature effect on mild steel corrosion in acid media in the presence of benzimidazole derivatives," Corrosion Science, vol. 45, no. 1, pp. 33-58, 2003.

[15] H. L. Wang, H. B. Fan, and J. S. Zheng, "Corrosion inhibition of mild steel in hydrochloric acid solution by a mercapto-triazole compound," Materials Chemistry and Physics, vol. 77, no. 3, pp. 655-661, 2003.

[16] M. Bouklah, N. Benchat, B. Hammouti, A. Aouniti, and S. Kertit, "Thermodynamic characterisation of steel corrosion and inhibitor adsorption of pyridazine compounds in $0.5 \mathrm{M}$ H2SO4," Materials Letters, vol. 60, no. 15, pp. 1901-1905, 2006.

[17] A. Popova, M. Christov, and A. Vasilev, "Inhibitive properties of quaternary ammonium bromides of N-containing heterocycles on acid mild steel corrosion. Part II: EIS results," Corrosion Science, vol. 49, no. 8, pp. 3290-3302, 2007.

[18] F. Bentiss, M. Lebrini, and M. Lagrenée, "Thermodynamic characterization of metal dissolution and inhibitor adsorption processes in mild steel/2,5-bis(n-thienyl)-1,3,4-thiadiazoles/ hydrochloric acid system," Corrosion Science, vol. 47, no. 12, pp. 2915-2931, 2005.

[19] H. S. Awad, "The effect of zinc-to-HEDP molar ratio on the effectiveness of zinc-1, hydroxyethylidene-1,1 diphosphonic acid in inhibiting corrosion of carbon steel in neutral solutions," Anti-Corrosion Methods and Materials, vol. 52, no. 1, pp. 22-28, 2005.

[20] M. Lebrini, M. Lagrenée, M. Traisnel, L. Gengembre, H. Vezin, and F. Bentiss, "Enhanced corrosion resistance of mild steel in normal sulfuric acid medium by 2,5-bis(n-thienyl)-1,3,4thiadiazoles: electrochemical, X-ray photoelectron spectroscopy and theoretical studies," Applied Surface Science, vol. 253, no. 23, pp. 9267-9276, 2007.

[21] M. Lebrini, M. Lagrenée, H. Vezin, M. Traisnel, and F. Bentiss, "Experimental and theoretical study for corrosion inhibition of mild steel in normal hydrochloric acid solution by some new macrocyclic polyether compounds," Corrosion Science, vol. 49, no. 5, pp. 2254-2269, 2007.
[22] M. Lebrini, F. Bentiss, H. Vezin, and M. Lagrenée, "The inhibition of mild steel corrosion in acidic solutions by 2,5-bis (4-pyridyl)-1,3,4-thiadiazole: structure-activity correlation," Corrosion Science, vol. 48, no. 5, pp. 1279-1291, 2006.

[23] M. Lebrini, F. Bentiss, N. E. Chihib, C. Jama, J. P. Hornez, and M. Lagrenée, "Polyphosphate derivatives of guanidine and urea copolymer: inhibiting corrosion effect of Armco iron in acid solution and antibacterial activity," Corrosion Science, vol. 50, no. 10, pp. 2914-2918, 2008.

[24] E. McCafferty, "Validation of corrosion rates measured by the Tafel extrapolation method," Corrosion Science, vol. 47, no. 12, pp. 3202-3215, 2005.

[25] E. Khamis, "Effect of temperature on the acidic dissolution of steel in the presence of inhibitors," Corrosion, vol. 46, no. 6, pp. 476-484, 1990.

[26] X. Li and G. Mu, "Tween-40 as corrosion inhibitor for cold rolled steel in sulphuric acid: weight loss study, electrochemical characterization, and AFM," Applied Surface Science, vol. 252, no. 5, pp. 1254-1265, 2005.

[27] T. Szauer and A. Brandt, "On the role of fatty acid in adsorption and corrosion inhibition of iron by amine-fatty acid salts in acidic solution," Electrochimica Acta, vol. 26, no. 9, pp. 1219-1224, 1981.

[28] S. S. Abd El Rehim, M. A. M. Ibrahim, and K. F. Khalid, "The inhibition of 4-(2'-amino- $5^{\prime}$-methylphenylazo $)$ antipyrine on corrosion of mild steel in $\mathrm{HCl}$ solution," Materials Chemistry and Physics, vol. 70, no. 3, pp. 268-273, 2001.

[29] K. J. Laidler, Reaction Kinetics, vol. 1, Pergamon Press, New York, NY, USA, 1st edition, 1963.

[30] A. K. Singh and M. A. Quraishi, "The effect of some bis-thiadiazole derivatives on the corrosion of mild steel in hydrochloric acid," Corrosion Science, vol. 52, no. 4, pp. 1373-1385, 2010.

[31] Z. Tao, S. Zhang, W. Li, and B. Hou, "Corrosion inhibition of mild steel in acidic solution by some oxo-triazole derivatives," Corrosion Science, vol. 51, no. 11, pp. 2588-2595, 2009.

[32] G. K. Gomma and M. H. Wahdan, "Schiff bases as corrosion inhibitors for aluminium in hydrochloric acid solution," Materials Chemistry \& Physics, vol. 39, no. 3, pp. 209-213, 1995.

[33] M. A. Amin, "Weight loss, polarization, electrochemical impedance spectroscopy, SEM and EDX studies of the corrosion inhibition of copper in aerated $\mathrm{NaCl}$ solutions," Journal of Applied Electrochemistry, vol. 36, no. 2, pp. 215-226, 2006.

[34] J. Flis and T. Zakroczymski, "Impedance study of reinforcing steel in simulated pore solution with tannin," Journal of the Electrochemical Society, vol. 143, no. 8, pp. 2458-2464, 1996.

[35] F. M. Donahue and K. Nobe, Journal of the Electrochemical Society, vol. 112, p. 886, 1965.

[36] E. Khamis, F. Bellucci, R. M. Latanision, and E. S. H. El-Ashry, "Acid corrosion inhibition of nickel by 2(triphenosphoranylidene) succinic anhydride," Corrosion, vol. 47, no. 9, pp. 677-686, 1991.

[37] E. A. Noor and A. H. Al-Moubaraki, "Thermodynamic study of metal corrosion and inhibitor adsorption processes in mild steel/1-methyl-4[4'(-X)-styryl pyridinium iodides/ hydrochloric acid systems," Materials Chemistry and Physics, vol. 110, no. 1, pp. 145-154, 2008.

[38] W. Durnie, R. D. Marco, A. Jefferson, and B. Kinsella, "Development of a structure-activity relationship for oil field corrosion inhibitors," Journal of the Electrochemical Society, vol. 146, no. 5, pp. 1751-1756, 1999. 
[39] G. Mu, X. Li, and G. Liu, "Synergistic inhibition between tween 60 and $\mathrm{NaCl}$ on the corrosion of cold rolled steel in 0.5 M sulfuric acid," Corrosion Science, vol. 47, no. 8, pp. 19321952, 2005.

[40] D. Do, Adsorption Analysis: Equilibria and Kinetics, Imperial College Press, New York, NY, USA, 1998. 

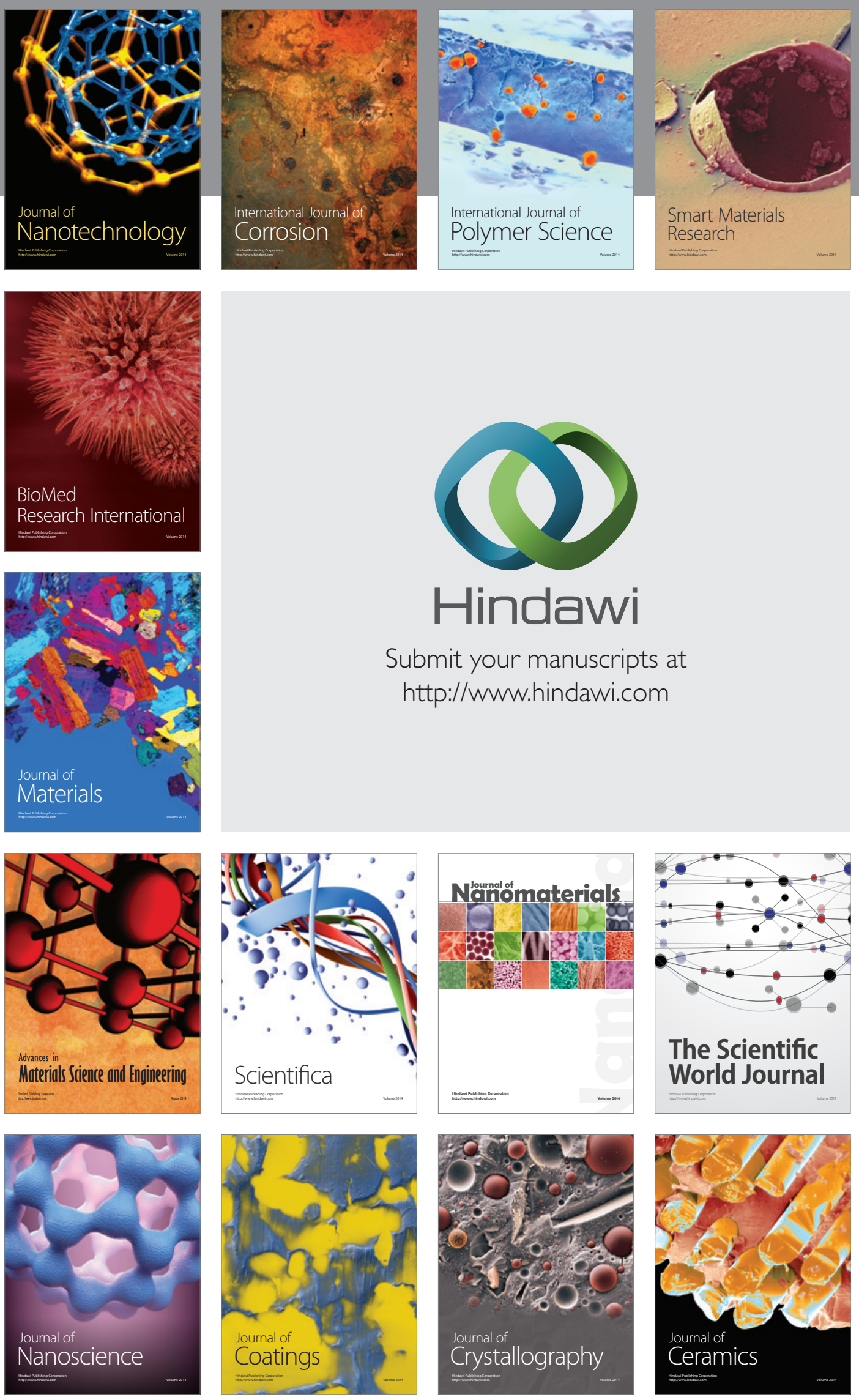

The Scientific World Journal

Submit your manuscripts at

http://www.hindawi.com

\section{World Journal}

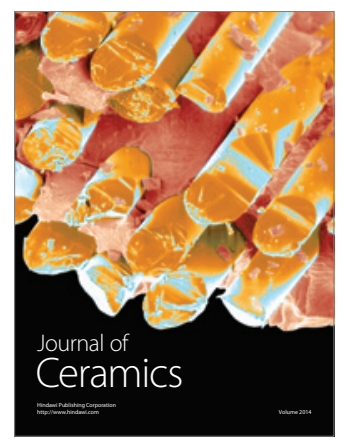

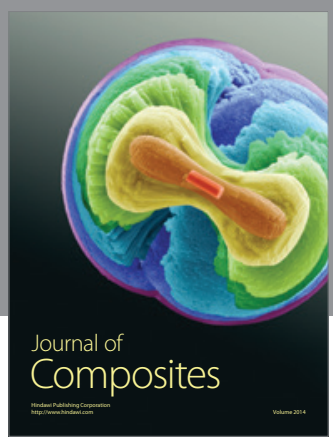
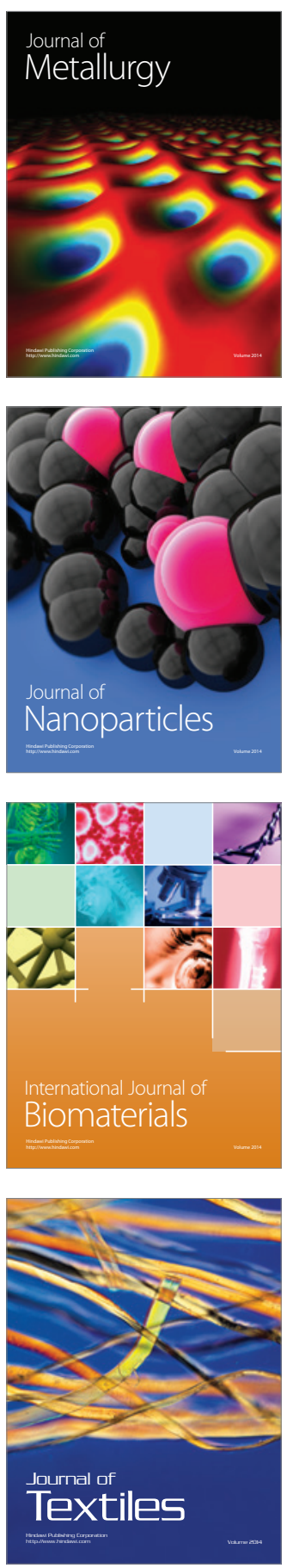